\title{
Anastomotic Sinus That Developed From Leakage After a Rectal Cancer Resection: Should We Wait for Closure of the Stoma Until the Complete Resolution of the Sinus?
}

\author{
Chris Tae-Young Chung, Se-Jin Baek, Jung-Myun Kwak, Jin Kim, Seon-Hahn Kim \\ Department of Surgery, Korea University College of Medicine, Seoul, Korea
}

Purpose: The aims of this study were to identify the clinical characteristics of an anastomotic sinus and to assess the validity of delaying stoma closure in patients until the complete resolution of an anastomotic sinus.

Methods: The subject patients are those who had undergone a resection of rectal cancer from 2011 to 2017, who had a diversion ileostomy protectively or therapeutically and who developed a sinus as a sequelae of anastomotic leakage. The primary outcomes that were measured were the incidence, management and outcomes of an anastomotic sinus.

Results: Of the 876 patients who had undergone a low anterior resection, 14 (1.6\%) were found to have had an anastomotic sinus on sigmoidoscopy or a gastrografin enema before their ileostomy closure. In the 14 patients with a sinus, 7 underwent ileostomy closure as scheduled, with a mean closure time of 4.1 months. The remaining 7 patients underwent ileostomy repair, but it was delayed until after the follow-up for the widening of the sinus opening by using digital dilation, with a mean closure time of 6.9 months. Four of those remaining seven patients underwent stoma closure even though their sinus condition had not yet been completely resolved. No pelvic septic complications occurred after closure in any of the 14 patients with an anastomotic sinus, but 2 of the 14 needed a rediversion due to a severe anastomotic stricture.

Conclusion: Patients with an anastomotic sinus who had been carefully selected underwent successful ileostomy closure without delay.

\section{Keywords: Anastomotic sinus; Anastomotic leakage; Ileostomy repair; Low anterior resection; Rectal neoplasm}

\section{INTRODUCTION}

Anastomotic leakage is a common and morbid complication of rectal surgery. It may threaten the structure of the anastomosis and is an important negative predictor of the functional outcome [1-4]. An anastomotic sinus is a sequela of anastomotic leakage in which the leak is confined to a blind ending tract $[5,6]$. The natural progression of an anastomotic sinus is not well known. Al-

Received: May 12, 2018 - Accepted: August 13, 2018

Correspondence to: Jin Kim, M.D.

Department of Surgery, Korea University College of Medicine, 73 Inchon-ro, Seongbuk-gu, Seoul 02841, Korea

Tel: +82-2-920-5346, Fax: +82-2-928-1631

E-mail: mrgs@korea.ac.kr

ORCID code: https://orcid.org/0000-0001-6479-9673

(C) 2019 The Korean Society of Coloproctology

This is an open-access article distributed under the terms of the Creative Commons Attribution NonCommercial License (http://creativecommons.org/licenses/by-nc/4.0) which permits unrestricted noncommercial use, distribution, and reproduction in any medium, provided the original work is properly cited. though its exact incidence is uncertain, approximately $2.8 \%-16 \%$ of patients who do not have a clinically evident leakage are found to have an anastomotic sinus after routine postoperative watersoluble contrast enema [5, 7-9].

Patients with an anastomotic sinus may have various symptoms, such as vague pelvic pain, discharge, bleeding, fever, and increased fecal frequency and urgency [10]. This makes postoperative management more complicated because of the potential risk of recurrent pelvic sepsis after the restoration of the intestinal continuity [7]. This can also delay the diverting stoma closure and require repeated evaluations and prolonged follow-up [10-12]. In addition, this may cause significant physical and psychological stress, which may lead to a poor quality of life for the patient. However, little information has been published on the natural progression of an anastomotic sinus, and the optimal strategy to manage the sinus is not well established $[5,10,13]$. In this study, the incidence, management and outcome of an anastomotic sinus secondary to leakage after a low anterior resection of rectal cancer were evalu- 
ated, and the validity of delaying stoma closure until the complete resolution of the sinus was assessed in selected patients through the lessons learned from our treatment experience.

\section{METHODS}

Patients who had undergone a rectal cancer resection followed by colorectal or coloanal anastomosis at Korea University Anam Hospital between September 2011 and April 2017 were evaluated. Patients who had undergone a preventive diversion ileostomy as their initial operation or who had undergone a therapeutic diversion ileostomy after developing an anastomotic leakage were selected. The following patients were excluded: patients with leakage who had been treated using Hartmann operation or reresection/reanastomosis or who had been managed with no diverting stoma. For this study, the patients who had been confirmed as having had an anastomotic sinus by using a gastrografin enema that had been performed prior to their ileostomy closure were evaluated. All the data were reviewed and analyzed retrospectively. This study was approved by the Institutional Review Board of Korea University Anam Hospital (IRB No. 2018AN0144), and all patients provided written informed consent.

In our unit, a diverting stoma is usually taken down 2-3 months after the primary surgery, and the intactness of the anastomosis is verified before stoma closure by using flexible sigmoidoscopy and gastrografin enema. An anastomotic sinus was defined as a track or groove with a blind ending that could be diagnosed by using a gastrografin enema or sigmoidoscopy as being different from a dog-ear of anastomosis as a result of a double-stapling anastomosis. A fistula to the skin or an adjacent organ and free leakage into the intra-abdominal space were exclusion criteria. When a sinus was found by using a gastrografin enema, a clinical judgment was made as to whether or not to delay the ileostomy closure based on the results from digital rectal examination (DRE), flexible sigmoidoscopy, and the gastrografin enema. Treatment strategies
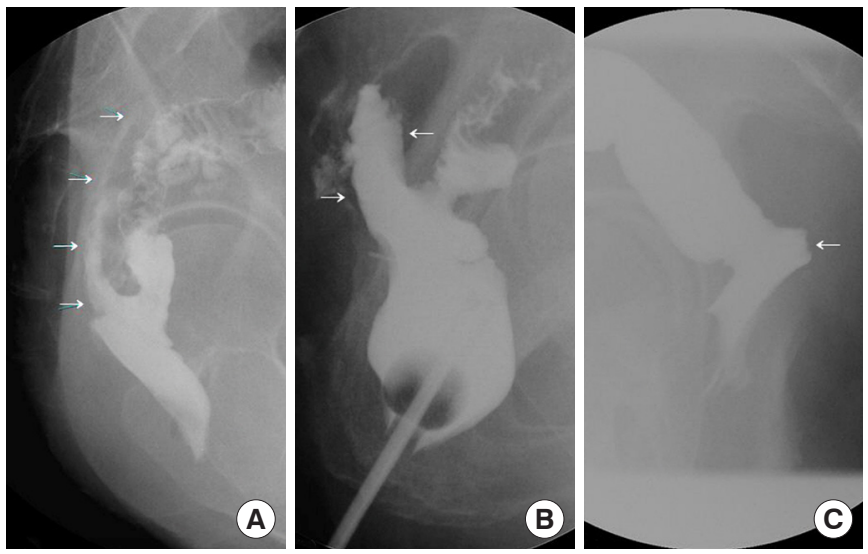

Fig. 1. Sinus types: linear (A), tubular (B), and concave (C). Arrows point to sinus. were formulated, as described below, based on initial experiences and were applied to subsequent cases. For this study, the sinuses were classified retrospectively by reviewing the available images.

The anastomotic sinus was classified according to its opening size, length and morphologic features. The opening size was defined based on the results of DRE and sigmoidoscopy as small ( $<10 \mathrm{~mm}$ in diameter) or large $(\geq 10 \mathrm{~mm}$ in diameter). The length was measured by using the gastrografin enema as short $(\leq 5 \mathrm{~cm})$ or long $(>5 \mathrm{~cm})$. The sinuses was classified into the following types: the 'linear' type, which was narrow with a small opening; the 'tubular' type, which was long compared to the opening with consistent width; and the 'concave' type, which was similar in length to or shorter than the opening (Fig. 1).

The management strategy formulated in our institution, although exceptional cases occur, is as follows (Fig. 2): The stoma closure was not delayed in cases with a large opening or a short length ( $5 \mathrm{~cm}$ or less), regardless of the type of sinus. In cases with a long sinus and with a small opening, closure was delayed, and the opening was widened with digital dilation during the delay to prevent collection of discharge in the cavity and to drain it more effectively. Digital dilation was performed in the same manner as DRE at the patient's bedside or in the outpatient clinic every week or every other week without specific preparation. The second finger was carefully inserted into the rectum to palpate the sinus opening around the anastomosis; then, the finger was gently pushed into the sinus to keep the opening with a one-finger width. During the procedure, patients experienced some anal discomfort, but the procedure was tolerable with no specific pain control. When detecting the sinus opening safely through a digital exam was difficult, the first dilation was performed under direct vision in the operating room after administration of general anesthesia, after which additional dilations were done at the patient's bedside.

The timing of closure was set based on clinical manifestations and the results of repeated gastrografin enemas and sigmoidosco-

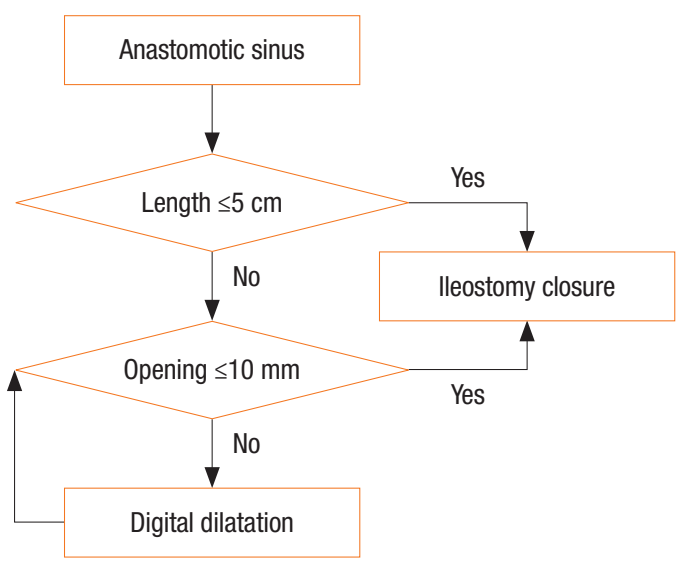

Fig. 2. Strategy for treating an anastomotic sinus. 


\section{Annals of \\ Anastomotic Sinus That Developed From Leakage After a Rectal Cancer Resection: Should We Wait}

for Closure of the Stoma Until the Complete Resolution of the Sinus?

\section{Coloproctology chris Tae-Young Chung, et al.}

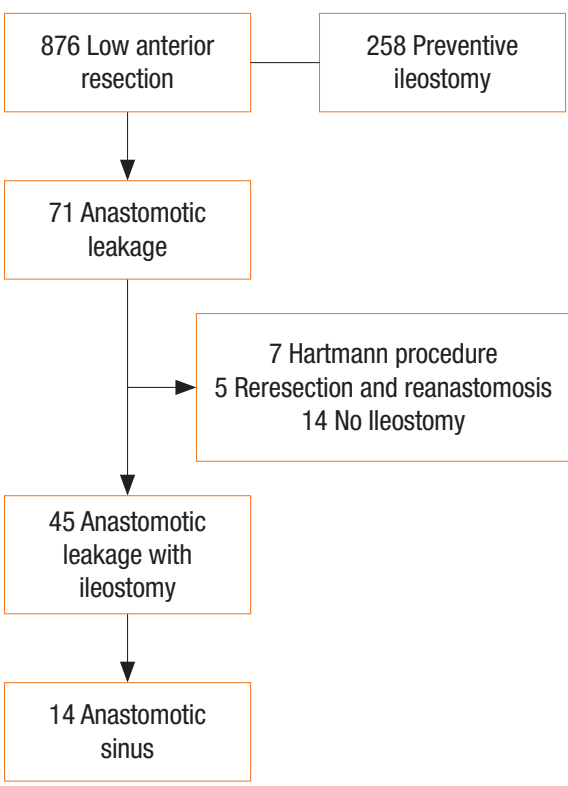

Fig. 3. Flowchart of the procedure for selecting the patients in this study.

pies. Our hypothesis was that if the opening was wide enough, no problems would be encountered after the resumption of bowel continuity. Therefore, even though the sinus was not completely resolved, the ileostomy was closed once clinical studies had verified the shortening or shrinkage of the sinus tract without sinusrelated symptoms such as pain or anal discharge. When the extent of the sinus was found to have expanded or sustained symptoms were present, we delayed the ileostomy closure. The success or failure of the ileostomy closure was judged clinically based on the recurrence of the leakage or pelvic sepsis. During the follow-up, we observed the clinical symptoms and performed physical examinations. In addition, we conducted abdominopelvic computed tomography (CT) and checked the recurrence of anastomotic leakage and pelvic abscess. The demographics, postoperative course, sinus-related information, and management and outcome of the ileostomy closure were collected for all patients.

\section{RESULTS}

A total of 876 patients had undergone a low anterior resection for primary rectal cancer during the time period of interest in this study, and 258 among them had undergone a preventive ileostomy (Fig. 3). Seventy-one of the 876 patients developed an anastomotic leakage (51 males [71.4\%] and 20 females [28.2\%]). Seven patients who had undergone a Hartmann procedure were excluded from the study because they had no anastomosis. The 5 patients who had undergone a reresection and reanastomosis were excluded because the new anastomosis was different from the previous anastomosis where the leakage had occurred. The 14 patients who had not undergone an ileostomy despite anasto-
Table 1. Clinical characteristics of patients with an anastomotic sinus $(\mathrm{n}=14)$

\begin{tabular}{|c|c|}
\hline Characteristic & Value \\
\hline \multicolumn{2}{|l|}{ Sex } \\
\hline Male & $10(71.4)$ \\
\hline Female & $4(28.6)$ \\
\hline Age (yr) & $58.6 \pm 10.8(39-74)$ \\
\hline Body mass index $\left(\mathrm{kg} / \mathrm{m}^{2}\right)$ & $24.1 \pm 3.1(16.9-30.1)$ \\
\hline Diabetes mellitus & $4(28.6)$ \\
\hline Preoperative chemoradiation & $5(35.7)$ \\
\hline \multicolumn{2}{|l|}{ Type of anastomosis } \\
\hline DST & $12(85.7)$ \\
\hline SST & $1(7.1)$ \\
\hline Hand-sewn & $1(7.1)$ \\
\hline \multicolumn{2}{|l|}{ Type of stoma } \\
\hline Preventive & $10(71.4)$ \\
\hline Therapeutic & $4(28.6)$ \\
\hline \multicolumn{2}{|l|}{ Type of leakage } \\
\hline Generalized peritonitis & $5(35.7)$ \\
\hline Localized abscess & $8(57.1)$ \\
\hline Subclinical & $1(7.1)$ \\
\hline \multicolumn{2}{|l|}{ Treatment of leakage } \\
\hline Ileostomy & $4(28.6)$ \\
\hline Peritoneal irrigation & $1(7.1)$ \\
\hline PAD & $7(50.0)$ \\
\hline Perianal l/D & $2(14.3)$ \\
\hline Transanal drainage & $2(14.3)$ \\
\hline Conservative management & $2(14.3)$ \\
\hline
\end{tabular}

Values are presented as number (\%) or mean \pm standard deviation (range).

DST, double-stapling technique; SST, single-stapling technique; PAD, percutaneous abscess drainage; l/D, incision and drainage.

motic leakage were excluded from the study because there was no ileostomy to reverse. Thus, 26 of the original 876 patients were excluded from this study. Of the 71 patients with anastomotic leakage, 45 had an ileostomy with anastomotic leakage while 14 had been diagnosed as having had an anastomotic sinus upon examination before their ileostomy closure.

Ten of the 14 patients (71.4\%) diagnosed as having had an anastomotic sinus were male, and the patients' mean age was 58.6 years (Table 1). Preoperative chemoradiation had been performed in $35.7 \%$ of those 14 patients. Furthermore, most $(85.7 \%)$ of the anastomosis procedures involving those 14 patients had been done with the double-stapling technique with a straight end-toend anastomosis. A diversion ileostomy had been performed protectively in $71.4 \%$ of those 14 patients as the initial operation and therapeutically in $28.6 \%$ as the second operation to manage leak- 
Table 2. Detailed description of patients with an anastomotic sinus

\begin{tabular}{|c|c|c|c|c|c|c|c|c|c|c|c|}
\hline $\begin{array}{l}\text { Patient } \\
\text { No. }\end{array}$ & $\begin{array}{l}\text { Sinus } \\
\text { opening }\end{array}$ & $\begin{array}{c}\text { Sinus } \\
\text { length } \\
(\mathrm{cm})\end{array}$ & $\begin{array}{l}\text { Sinus } \\
\text { type }\end{array}$ & $\begin{array}{l}\text { Preop- } \\
\text { erative } \\
\text { CRT }\end{array}$ & $\begin{array}{l}\text { Type of } \\
\text { Stoma }\end{array}$ & $\begin{array}{l}\text { Delay of } \\
\text { closure }\end{array}$ & $\begin{array}{l}\text { Repetition } \\
\text { of Image }\end{array}$ & $\begin{array}{l}\text { Remnant } \\
\text { sinus }\end{array}$ & $\begin{array}{l}\text { Time to } \\
\text { reversal } \\
(\mathrm{mo})\end{array}$ & $\begin{array}{l}\text { Follow-up } \\
\text { duration } \\
\text { (mo) }\end{array}$ & Outcome \\
\hline 1 & Small & 2 & Linear & No & Preventive & No & $\mathrm{N} / \mathrm{A}$ & $\mathrm{N} / \mathrm{A}$ & 5.1 & 31.1 & Reoperation due to anastomotic stricture \\
\hline 2 & Small & 5 & Linear & No & Therapeutic & No & $\mathrm{N} / \mathrm{A}$ & N/A & 2.9 & 51.2 & Healed \\
\hline 3 & Small & 7 & Linear & No & Therapeutic & No & $\mathrm{N} / \mathrm{A}$ & $\mathrm{N} / \mathrm{A}$ & 4.4 & 50.1 & Healed \\
\hline 4 & Small & 5 & Linear & Yes & Preventive & Yes & 1 & Yes (tubular) & 8.9 & 33.3 & Persistent sinus without a problem \\
\hline 6 & Small & 10 & Linear & Yes & Preventive & Yes & 2 & No & 5.2 & 21.4 & Success \\
\hline 7 & Small & 15 & Linear & Yes & Preventive & Yes & 2 & Yes (tubular) & 4.2 & 26.5 & Healed \\
\hline 8 & Small & 15 & Linear & No & Preventive & Yes & 2 & Yes (concave) & 3.2 & 25.7 & Anastomotic stricture without a problem \\
\hline 9 & Small & 5 & Tubular & Yes & Preventive & No & N/A & N/A & 2.7 & 21.3 & Healed \\
\hline 13 & Large & 2 & Concave & Yes & Preventive & Yes & 1 & No & 14.7 & 6.0 & Success \\
\hline 14 & Large & 3 & Concave & No & Preventive & Yes & 1 & No & 7.0 & 53.1 & Success \\
\hline
\end{tabular}

CRT, chemoradiation; N/A, not available.

age. The leakage pattern indicated generalized peritonitis in 5 of those 14 patients (35.7\%), localized abscess in $8(57.1 \%)$, and a subclinical condition in 1 (7.1\%). Among those 14 patients, relaparoscopic operation under general anesthesia had been performed in $5(35.7 \%)$ to manage the leaks, perianal or transanal drainage had been performed in 4 (28.6\%), and ultrasonography (US)- or CT-guided transabdominal or transgluteal percutaneous abscess drainage (PAD) had been applied in 7 (50.0\%). Four patients $(28.6 \%)$ had been treated using combined reoperation and PAD.

In the 14 patients with an anastomotic sinus, 7 underwent ileostomy closure as planned without delay. Five of the 7 patients had a short sinus of $5 \mathrm{~cm}$ or less (Table 2). The mean time to the ileostomy closure in these 7 patients was $4.1 \pm 1.1$ months (range, 2.75.5 months). Two of those 7 required a reoperation eventually. The remaining 7 patients underwent delayed ileostomy closure. The mean length of the sinus of these 7 patients was $8.1 \pm 5.4 \mathrm{~cm}$ (range, 2-15 cm), and 5 of the 7 patients had a linear-type sinus. Four of these remaining seven patients underwent stoma closure even though their sinus had not been resolved completely. The mean time to closure in the delayed closure group was $6.9 \pm 3.9$ months (range, 3.2-14.7 months).

Overall, the mean time to closure for the patients with an anastomotic sinus was $5.5 \pm 3.1$ months (range: $2.7-14.7$ months). During the follow-up that covered a mean of 33.5 months (range, 6.0-54.6 months), no closure failures or pelvic sepsis problems, such as recurrent leakage or abscess, were encountered. Five of the 7 patients who underwent stoma closure as planned showed complete sinus healing in their follow-up studies, but 2 patients required rediversion due to an anastomotic stricture after their ileostomy closure. The sinuses were healed completely in the follow-up studies on 5 of the 7 patients in the delayed ileostomy closure group, but 1 patient showed an asymptomatic, persistent sinus in the follow-up sigmoidoscopy or gastrografin enema and another patient had an asymptomatic anastomotic stricture.

\section{DISCUSSION}

An anastomotic sinus is an uncommon sequela in which leakage occurs in a coloanal or a low colorectal anastomosis. This study demonstrated a $1.6 \%$ anastomotic sinus rate after rectal cancer resection, which is a low rate compared with the $2.8 \%-16 \%$ reported in other studies [5, 7-9]. Although the optimal management of an anastomotic sinus is not well known due to the rarity of its occurrence, many surgeons choose primarily to delay ileostomy closure and repeat the radiologic exam, hoping for eventual spontaneous healing $[5,8,10,11]$. Several procedures have been attempted to reduce the size of the sinus, including debridement, mucosal advancement and sinus closure $[5,8,11,14,15]$. The use of fibrin glue for sinus closure was also recently reported by Swain and Ellis [16] and has been reported to be relatively effective with a small sinus. However, the effect was weak in a large sinus, and no definitive method for treating an anastomotic sinus has been accepted until now.

Finding studies that report on immediate stoma closure in anastomotic sinus patients, such as in this study, is difficult, even though we have performed such a procedure in carefully selected patients. We hypothesized that if the leakage is contained in a 
blind sinus with a wide opening to the lumen, ileostomy closure before complete healing should not affect the clinical outcome. All patients in this study who underwent stoma closure according to the hypothesis recovered well with neither septic complications in the pelvis nor fistula formation. Therefore, the existence of the sinus itself is not believed to be associated directly with sepsis problems after the restoration of intestinal continuity.

The most important point of our ileostomy closure decision was the size of the sinus opening. Although the length and the type were also important, an appropriate-sized opening must be maintained to ensure natural drainage and spontaneous healing of the sinus. We think that effective drainage is important to sinus management. Digital dilatation might enable effective abscess drainage through an extension of the sinus opening and might facilitate wound healing and shorten the sinus track. Thus, in the seven patients with delayed closure, the sinus opening was repeatedly widened using periodic digital dilation, which enabled successful management of those patients. The procedure that was used in this study is somewhat similar to the deroofing technique of Whitlow et al. [6]. This technique is performed by dividing the wall between the presacral sinus and the adjacent bowel lumen under direct vision through a rigid proctoscope. It allows free drainage of the abscess collected in the sinus cavity and healing by secondary intention and has been reported to have good results. While the procedure requires general anesthesia, our technique can be performed bedside and is regarded as an easy, safe and effective method of sinus management. Another recent development was the introduction of the endo-sponge technique by Weidenhagen et al. [17] It uses low-vacuum suction through a sponge inserted into the presacral space, which leads to the gradual closure of the sinus [18-21]. The deroofing and endo-sponge techniques are similar to our management technique in that they induce healing via proper drainage.

The overall mean time to closure for all 14 patients with an anastomotic sinus was 5.5 months, and that for the 7 patients who underwent delayed closure was only 6.9 months, which is not inferior to the results of other studies. The timing of the ileostomy closure was not set based on the complete healing of the sinus, and no septic problems after the ileostomy closure were reported, even when the sinus remained. Until now, the ideas that delaying ileostomy closure until complete healing of the sinus has no additional benefit in terms of the clinical outcome and can lead to the development of stoma-related problems have been implicitly accepted. However, if delayed closure is overlooked, as it often is, the adverse effects of that delay cannot be ignored. Moreover, even though the delay may be temporary, the stoma remains a major psychological handicap and causes significant physical stress that leads to a poor quality of life [22-24]. Therefore, any unnecessary delay in stoma closure should be avoided.

Meanwhile, the possibility of stoma closure in patients with a sinus does not guarantee a good outcome for other clinical manifestations because an inherent problem of an anastomosis is the development of a sinus. In this study, 2 patients needed a reoperation for diversion due to a severe anastomotic stricture after stoma closure. In particular, a poor functional outcome can be predicted in such circumstances. One patient (patient 1) experienced anastomotic disruption after the initial operation. He underwent stoma closure without delay because a short linear sinus was shown on sigmoidoscopy and the gastrografin enema before stoma closure. No other anastomotic problem was shown in the preoperative studies, but an anastomotic stricture developed after the stoma closure. Another patient (patient 11) showed a moderate anastomotic stricture on sigmoidoscopy before his stoma closure, but he underwent manual dilation and stoma closure without delay. Therefore, a decision should be carefully made on stoma closure and its timing in cases of patients who have had an extensive anastomotic disruption or such a condition combined with other anastomotic problems such as a stricture.

This study had some limitations. First, this was not a comparative study, and only a few cases were reviewed. Randomization was difficult due to the characteristics of the sinus and the rarity of occurrence of the condition. A multicenter study may enhance the evidence. Second, the sinus classification was ambiguous, and even our study had cases that did not follow our classification strategy. Patients 4, 13, and 14 (Table 2) did not need delayed stoma closure according to our management strategy, but their stoma closures were delayed anyway. On the other hand, patient 3 underwent ileostomy closure without delay, although he should have been considered for delay and his sinus opening should have been widened with digital dilation management. Fortunately, he did not suffer any specific problems postoperatively, but he may suffer from a recurrent abscess in the future. In such cases, the treatment protocol was arrived at through trial and error. Third, the definitions of early and delayed stoma closure were also vague. For example, some patients in the delayed group had a lower range of time points of stoma closure than some in the early group. Some patients were adjudged to have had inconsistent stoma closure from their first examination and then to have undergone stoma closure after a short-term follow-up examination. Such patients were, of course, regarded as belonging to the delayed-closure group.

Despite these limitations, this study is significant. It classified sinuses based on their morphologic features, unlike in other studies, which categorized them according to the clinical severity of the leakage. The method used herein is easier and more objective. In addition, in this study, immediate stoma closure was found to be possible in patients with carefully selected sinuses; furthermore, stoma closure in patients with a remnant sinus can be performed successfully without recurrence of sepsis problems. We believe that this study can provide valuable information for the early closure of stomas in patients with an anastomotic sinus and can help to reduce unnecessary inconvenience and anxiety.

In conclusion, ileostomy closure is possible without delay in cases of carefully selected sinuses. Effective drainage and healing 
can be expected when the sinus opening is widened via digital dilation during the delay period. Successful stoma closure is possible even if the sinus has not completely healed. A prospective randomized trial in a larger population is needed to clarify the treatment strategy for an anastomotic sinus.

\section{CONFLICT OF INTEREST}

No potential conflict of interest relevant to this article was reported.

\section{REFERENCES}

1. Nisar PJ, Kiran RP, Shen B, Remzi FH, Fazio VW. Factors associated with ileoanal pouch failure in patients developing early or late pouch-related fistula. Dis Colon Rectum 2011;54:446-53.

2. Forbes SS, O'Connor BI, Victor JC, Cohen Z, McLeod RS. Sepsis is a major predictor of failure after ileal pouch-anal anastomosis. Dis Colon Rectum 2009;52:1975-81.

3. Ptok H, Marusch F, Meyer F, Schubert D, Gastinger I, Lippert H, et al. Impact of anastomotic leakage on oncological outcome after rectal cancer resection. Br J Surg 2007;94:1548-54.

4. Nesbakken A, Nygaard K, Lunde OC. Outcome and late functional results after anastomotic leakage following mesorectal excision for rectal cancer. Br J Surg 2001;88:400-4.

5. Akbari RP, Madoff RD, Parker SC, Hagerman G, Minami S, Bullard Dunn KM, et al. Anastomotic sinuses after ileoanal pouch construction: incidence, management, and outcome. Dis Colon Rectum 2009;52:452-5.

6. Whitlow CB, Opelka FG, Gathright JB Jr, Beck DE. Treatment of colorectal and ileoanal anastomotic sinuses. Dis Colon Rectum 1997;40:760-3.

7. van Koperen PJ, van der Zaag ES, Omloo JM, Slors JF, Bemelman WA. The persisting presacral sinus after anastomotic leakage following anterior resection or restorative proctocolectomy. Colorectal Dis 2011;13:26-9.

8. Arumainayagam N, Chadwick M, Roe A. The fate of anastomotic sinuses after total mesorectal excision for rectal cancer. Colorectal Dis 2009;11:288-90.

9. Khair G, Alhamarneh O, Avery J, Cast J, Gunn J, Monson JR, et al. Routine use of gastrograffin enema prior to the reversal of a loop ileostomy. Dig Surg 2007;24:338-41.

10. Ahmed Ali U, Shen B, Remzi FH, Kiran RP. The management of anastomotic pouch sinus after IPAA. Dis Colon Rectum 2012;55 541-8.

11. Nyam DC, Wolff BG, Dozois RR, Pemberton JH, Mathison SM.
Does the presence of a pre-ileostomy closure asymptomatic pouch-anastomotic sinus tract affect the success of ileal pouchanal anastomosis? J Gastrointest Surg 1997;1:274-7.

12. Lee WS, Yun SH, Roh YN, Yun HR, Lee WY, Cho YB, et al. Risk factors and clinical outcome for anastomotic leakage after total mesorectal excision for rectal cancer. World J Surg 2008;32:11249.

13. Fong SS, Chen K, Sim R. Chronic anastomotic sinus after low anterior resection: when can the defunctioning stoma be reversed? Colorectal Dis 2011;13:644-9.

14. Korsgen S, Nikiteas N, Ogunbiyi OA, Keighley MR. Results from pouch salvage. Br J Surg 1996;83:372-4.

15. Lohsiriwat V, Clark SK. Persistent perineal sinus after ileoanal pouch excision in inflammatory bowel diseases: incidence, risk factors, and clinical course. Dis Colon Rectum 2008;51:1795-9.

16. Swain BT, Ellis CN. Fibrin glue treatment of low rectal and pouch-anal anastomotic sinuses. Dis Colon Rectum 2004;47:2535.

17. Weidenhagen R, Gruetzner KU, Wiecken T, Spelsberg F, Jauch KW. Endoscopic vacuum-assisted closure of anastomotic leakage following anterior resection of the rectum: a new method. Surg Endosc 2008;22:1818-25.

18. Mees ST, Palmes D, Mennigen R, Senninger N, Haier J, Bruewer M. Endo-vacuum assisted closure treatment for rectal anastomotic insufficiency. Dis Colon Rectum 2008;51:404-10.

19. Nagell CF, Holte K. Treatment of anastomotic leakage after rectal resection with transrectal vacuum-assisted drainage (VAC). A method for rapid control of pelvic sepsis and healing. Int J Colorectal Dis 2006;21:657-60.

20. Riss S, Stift A, Meier M, Haiden E, Grünberger T, Bergmann M. Endo-sponge assisted treatment of anastomotic leakage following colorectal surgery. Colorectal Dis 2010;12(7 Online):e104-8.

21. van Koperen PJ, van Berge Henegouwen MI, Rosman C, Bakker CM, Heres P, Slors JF, et al. The Dutch multicenter experience of the endo-sponge treatment for anastomotic leakage after colorectal surgery. Surg Endosc 2009;23:1379-83.

22. Gooszen AW, Geelkerken RH, Hermans J, Lagaay MB, Gooszen HG. Quality of life with a temporary stoma: ileostomy vs. colostomy. Dis Colon Rectum 2000;43:650-5.

23. Khoo RE, Cohen MM, Chapman GM, Jenken DA, Langevin JM. Loop ileostomy for temporary fecal diversion. Am J Surg 1994; 167:519-22.

24. O'Leary DP, Fide CJ, Foy C, Lucarotti ME. Quality of life after low anterior resection with total mesorectal excision and temporary loop ileostomy for rectal carcinoma. Br J Surg 2001;88:1216-20. 